\title{
A Case-Referent Study of Extrapyramidal Signs (Preparkinsonism) in Rural Communities of Israel
}

\author{
Y.O. Herishanu, E. Kordysh and J.R. Goldsmith
}

\begin{abstract}
Background: In previous studies we reported an increased prevalence of Parkinson's disease in several kibbutzim of Southern Israel (cluster kibbutzim). Subsequent studies revealed a significant prevalence of subjects presenting extrapyramidal signs (preparkinsonism) in the same kibbutzim. On follow-up worsening of these signs was observed in some of the older subjects, some of them actually being diagnosed as suffering from l-Dopa responsive Parkinson's disease. The current study was designed to evaluate possible etiologic factors for the development of preparkinsonism. Methods: 317 subjects over the age of 40, living in five kibbutzim were examined and interviewed. 95 subjects presenting extrapyramidal signs were compared with 95 control subjects. They were matched for age, sex and length of residence in the kibbutz. Odds ratios were computed to identify exposure variables for logistic regression analyses. Detectors for carbamates and organic phosphates were applied at different sites of these kibbutzim. Results: The severity and frequency of the extrapyramidal signs were higher in the older age groups, more in the "cluster", than in other kibbutzim. A very strong association was found between field crop work exposure, particularly cotton, and preparkinsonism $(p=0.0007)$ and a slightly weaker association for landscape work. The detectors picked up abundant pesticide traces (carbamates and organic phosphates) in the residential areas fairly distant from sites of aerial spray. Conclusions: We assume a chronic passive exposure of the residents in these kibbutzim to pesticides, in addition to any occupational exposures.
\end{abstract}

RÉSUMÉ: Une étude cas-témoin dans des localités rurales en Israël sur la prévalence de signes extrapyramidaux. Introduction: Nous avons rapporté dans des études antérieures une augmentation de la prévalence de la maladie de Parkinson dans plusieurs kibboutz du sud d'Israël (kibboutz à haute prévalence). Des études ultérieures ont montré une prévalence significative de sujets présentant des signes extrapyramidaux (préparkinsonisme) dans les mêmes kibboutz. Avec le temps, nous avons observé une aggravation de ces signes chez quelques sujets plus âgés dont certains ont reçu un diagnostique de maladie de Parkinson répondant à la L-Dopa. Cette étude a été conçue pour évaluer les facteurs étiologiques possibles du préparkinsonisme. Méthodes: 317 sujets âgés de plus de 40 ans et demeurant dans cinq kibboutz ont été examinés et interrogés. 95 sujets présentant des signes extrapyramidaux ont été comparés à 95 sujets contrôles. Ils ont été appariés pour l'âge, le sexe et le temps de résidence dans le kibboutz. Nous avons utilisé le risque relatif pour identifier des variables d'exposition afin de procéder à des analyses de régression logistique. Des détecteurs de carbamates et de phosphates organiques ont été appliqués à différents sites de ces kibboutz. Résultats: La sévérité et la fréquence des signes extrapyramidaux étaient plus élevées dans les groupes d'âges plus avancés et davantage dans la zone à haute prévalence que dans les autres kibboutz. Nous avons observé une association très forte entre l'exposition dans le cadre de travaux agraires, particulièrement la culture du coton, et le préparkinsonisme $(\mathrm{p}=0.0007)$ et une association légèrement plus faible avec les travaux de paysagement. Les détecteurs ont indiqué des traces abondantes de pesticides (carbamates et phosphates organiques) dans les zones résidentielles assez éloignées des sites d'arrosages aériens. Conclusions: Nous présumons qu'il existe une exposition chronique passive des résidents de ces kibboutz aux pesticides en plus d'une exposition occupationnelle.

Can. J. Neurol. Sci. 1998; 25: 127-133

Parkinson's disease is a common neurological condition with a prevalence ranging between $164.2 / 100,000$ in Scotland' to $57.9 / 100,000$ in the Negev (Southern Israel). ${ }^{2}$ Its etiology is still unknown, but there is some evidence that environmental factors might play a pathogenic role interacting with a background of slow, sustained neuronal loss due to advancing age. ${ }^{3}$ Three independent studies ${ }^{4-6}$ on early onset Parkinson's disease reported a correlation between rural residence early in life and occurrence of the disease. In another study, Tanner et al., ${ }^{7}$ found a higher rate of farming background in patients with early Parkinson's disease than in controls. Additional studies linked rural living ${ }^{8-15}$ to the risk for Parkinson's disease and some specifically pinpointed wellwater or its constituents as the feature of rural life most tightly associated with the risk for Parkinson's disease. . $^{2}$ 8-11.13. 16-18

In 1989 we reported a significantly increased prevalence of
Parkinson's disease in three adjacent agricultural settlements (kibbutzim) in southern Israel. ${ }^{2}$ Between 1981-1988 the average annual incidence of Parkinson's disease in the population above the age of 40 in these kibbutzim (637 people) was $15.7 / 10,000$ $(\mathrm{N}=8)$ it increased to $27.5(\mathrm{~N}=8)$ for $1989-1992$ and reached an average annual incidence of $47.1 / 10,000(\mathrm{~N}=12)$ in the years 1993-1996. Long term residence in the same area and a shared aquifer, along with agricultural occupations and exposures were common to these three communities.

From the Department of Neurology (Y.O.H.), Soroka Medical Center and Unit of Epidemiology (E.K., J.R.G.), Goldman Faculty of Health Sciences, Ben-Gurion University of the Negev, Beer-Sheva, Israel.

RECEIVED FEBRUARY 27, 1997. ACCEPTED IN FINAL FORM NOVEMBER $11,1997$.

Reprint requests to: Yuval O. Herishanu, Department of Neurology, Soroka Medical Center, P.O. Box 151, Beer-Sheva 8410, Israel 
A prospective study ${ }^{19.20}$ done in two of these settlements, on asymptomatic people over forty, revealed extrapyramidal signs* in $49 \%$ of 114 persons compared to $8.2 \%$ of 110 from other communities (mainly urban) in our region. ${ }^{20}$ These signs consisted mostly of rigidity and bradykinesia of varying severity as measured by Webster scale. On follow-up, worsening of the signs especially among the older subjects was noted. ${ }^{21}$ Since 1990, 14 new cases of Parkinson's disease (among the age group of 65 and over), were diagnosed by family doctors. The diagnoses were confirmed by certified neurologists, and the patients are currently 1-Dopa treated. Some of these patients were previously included in our prospective study and were found to have extrapyramidal signs. ${ }^{19.20}$ These observations suggest that these extrapyramidal signs and Parkinson's disease might be stages of the same disorder rather than two distinct entities.

Olfactory discrimination testing in 20 persons among those presenting extrapyramidal signs during four years of follow-up, revealed a decline in their capability to discriminate odors. These changes did not significantly differ from those observed in controls or in Parkinsonian patients and thus did not set the preparkinsonians apart as a distinct group. ${ }^{21}$

Bennett et al. ${ }^{22}$ identified in a sample of 467 persons over 65 , 159 who had at least two stigmata associated with Parkinson's Disease and they considered them to have Parkinsonism. On follow-up for nine years, excess mortality was found in subjects with Parkinsonism, especially among those with gait disturbances. This study also documented the sharp increase of Parkinsonism with age. While these authors use a different definition of Parkinsonism than we do for preparkinsonism, there is still no ground to suspect that the same processes would not involve both groups, and therefore, there is reason to try to identify environmental factors which might contribute to development of preparkinsonism and Parkinson's disease.

In order to assess the possible role of pesticide and other chemical exposures in the increased prevalence of preparkinsonism in these communities, we examined life-long occupational and sociodemographic features of the people with preparkinsonian signs compared to those of "unaffected" individuals in several kibbutzim. We also used air and soil analysis to evaluate environmental contamination in the residential areas of these kibbutzim.

\section{Methods and SubJects}

317 asymptomatic persons from five kibbutzim (including the three studied in 1989, and called "cluster" kibbutzim), who volunteered to participate in this study, were examined by three certified neurologists and any extrapyramidal signs present were scored according to Webster's Parkinson's disease rating scale (Appendix 1). Persons with a score equal to 2 and above, were considered as having extrapyramidal signs, or preparkinsonism (PP). No PD patient was included in this study.

All the subjects underwent cognitive function evaluation by Mini Mental Status Examination (MMSE), and a score of less than 26 points was considered indicative of cognitive decline. University of Pennsylvania Smell Identification Test (USPIT) ${ }^{23}$ was administered to all the subjects not having nasal obstruction.
Information was collected by means of a previously validated questionnaire, administered by three interviewers, who were blinded to the clinical findings. The questionnaire included demographic data on age, gender, place of birth, size of the birth community, father's and mother's country of birth, date of immigration, and a history of incarceration in a concentration or extermination camp, ghetto or prison. Each type of residence for more than 6 months, water source in every residence, and occupation for more than 6 months, with emphasis on agricultural occupations (e.g., orchard, field, greenhouse, work with livestock, etc.), were recorded. The subjects were asked about any occupational or household use of pesticides, herbicides, fungicides. There were questions on past medical history, hospital admissions, surgery, trauma and chronic drug treatment. Lifetime smoking histories were obtained as well as data on alcohol consumption, drug abuse and dietary habits. A comprehensive list of all the pesticides, herbicides and fungicides used in the last forty years was obtained from each kibbutz management. The neurologists and the interviewers were blinded as to whether the subjects were from a "cluster" or "noncluster" kibbutz.

Out of the subjects with extrapyramidal signs a case group defined by Webster score equal to 2 or more was selected and compared to a referent (Webster score less than 2) group matched for age, sex and duration of residence in the kibbutz. Each group contained 95 subjects.

Eleven samples of soil were collected from the residential area of the kibbutzim and from adjacent fields, and were analyzed, after organic or water extraction, for organic phosphorus compounds by gas chromatography, for paraquat and diquat by high pressure liquid chromatography and for mancozeb by ICP.

Detectors (The Enzytec Program, Scanmedical International SMI AS, Denmark) for detection of organic phosphorus and carbamates in the air, were applied to trees and walls of the houses, at distances greater than 500 metres from the sites of aerial spray of the fields. The detectors were collected 4 hours later and analyzed.

Statistical analysis was performed on the SPSS statistical software package using chi-square tests, Mantel-Haenszel, Fisher exact test (where appropriate), Pearson correlation, "Student" $t$ test and logistic regression (univariate and multivariate analyses).

\section{RESULTS}

\section{Neurological Findings}

197 subjects were examined in the 3 "cluster" kibbutzim and 120 subjects in the other two. The age by sex distribution of the entire population above the age of 40 , of those included in the study and of those presenting extrapyramidal signs are presented in Table 1. Extrapyramidal signs (Webster score 2 and above) were found in $46.4 \%$ of the subjects from "cluster" kibbutzim and in only $22.5 \%$ of those living in the other two kibbutzim. When age was taken into account, the excess PP in cluster kibutzim was significant by sign test, but not by MantelHaenszel test. The frequency and severity of these signs were

*Based on the criterion of Webster score of 2 or more we designate such persons as having "preparkinsonism". Analogously with premalignant lesions, we think of this group as potential Parkinson's disease patients, but the use of the term is not intended to have any prognostic significance. 
Table 1: Kibbutz population, sample and persons with Webster score 2+.

\begin{tabular}{|c|c|c|c|c|c|c|}
\hline \multirow[b]{2}{*}{ Age } & \multicolumn{2}{|c|}{$\underset{\mathbf{N}}{\text { Population }}$} & \multicolumn{2}{|c|}{$\begin{array}{l}\text { Of the population } \\
N(\%) \text { of sample }\end{array}$} & \multicolumn{2}{|c|}{$\begin{array}{c}\text { Of the sample } \\
\mathrm{N}(\%) \text { of Webster } 2+\end{array}$} \\
\hline & $\mathbf{M}$ & $\mathbf{F}$ & $\mathbf{M}$ & $\mathbf{F}$ & $\mathbf{M}$ & $\mathbf{F}$ \\
\hline \multicolumn{7}{|c|}{ Cluster kibbutzim } \\
\hline $40-60$ & 155 & 163 & $30(19)$ & $55(33)$ & $5(17)$ & $16(29)$ \\
\hline $61-70$ & 105 & 112 & $21(20)$ & $30(27)$ & $13(62)$ & $14(47)$ \\
\hline $71+$ & 44 & 58 & $34(77)$ & $26(45)$ & $26(77)$ & $17(42)$ \\
\hline All & 304 & 333 & $85(28)$ & $111(33)$ & $44(52)$ & $47(42)$ \\
\hline \multicolumn{7}{|c|}{ Non-cluster kibbutzim } \\
\hline $40-60$ & 133 & 144 & $23(17)$ & $34(24)$ & $3(13)$ & $7(21)$ \\
\hline $61-70$ & 57 & 53 & $26(46)$ & $29(55)$ & $5(19)$ & $12(41)$ \\
\hline $71+$ & 68 & 43 & $6(9)$ & $3(7)$ & $1(17)$ & $0(0)$ \\
\hline All & 258 & 240 & $55(21)$ & $66(28)$ & $9(16)$ & $19(29)$ \\
\hline
\end{tabular}

higher in the older age groups. Elderly subjects living in the "cluster" kibbutzim showed more extrapyramidal signs than those living in the other kibbutzim. There was no gender predominance in the appearance of these signs.

Bradykinesia of hands was the most frequent sign. Unilateral bradykinesia was found in 50 subjects, and bilateral signs were present in 19. Decreased upper extremity swing was unilateral in 22 subjects and bilateral in 10. Rigidity and cogwheeling was found in the four limbs in 18 subjects and associated with activation phenomenon in 28 subjects. Resting tremor of the hands was seen in 7 persons. Facies immobility was observed in 3 subjects. Postural abnormalities were seen in 8 and gait difficulties in 2 . Seborrhea was seen in 5. Additionally, glabella tap response was noticed in 8 subjects. Five subjects had a Webster score higher than 8 .

Impaired cognitive functions were more frequent in the group with signs of preparkinsonism, especially in the subjects aged $61-70$ in comparison with the control group $(p<0.01)$.

Smell discrimination was not significantly impaired in subjects with extrapyramidal signs in comparison with the controls.

\section{Epidemiological Analysis}

Results of case-referent analyses of extrapyramidal signs prevalence by other variables (Table 2):

Demographic: those who immigrated at ages less than 25 years are less likely to have PP by univariate analysis, but not significantly so in multivariate analysis $(\mathrm{N}=142)$.

Pre-kibbutz exposure: Those who lived near farms at age 014 are less likely to have PP in univariate analyses but not in multivariate analyses. Camp, war, or ghetto experience at ages 0-14 is associated with decreased likelihood of PP with borderline significance in univariate analyses but clearly significant in multivariate analysis $(\mathrm{N}=13)$.

Kibbutz exposure: Field work history is highly significant in both univariate and multivariate analysis, and involves 46 persons. The odds ratio is 7 for multivariate analysis. The type of field crop which is most associated with preparkinsonism is cotton (Table 3) (Figure). Landscape work history is also highly significant in multivariate analysis but of borderline significance in univariate analysis. It involves 10 respondents and has an odds ratio with multivariate analysis of 37 . By contrast, work history in workshops is negatively associated with risk of PP, significantly so in multivariate analysis but of borderline significance in univariate analysis.
Life style and diet: Frequent use of alcoholic beverages is negatively associated with prevalence of PP in both univariate and multivariate analyses. Cigarette smoking is not associated with the condition in either type of analysis. Having reported 12 hobbies up to age 25 , is significantly negatively associated with PP in multivariate analysis but not in univariate analysis, while 2 or more hobbies in the period up to 25 years is positively associated, but not quite significantly in either univariate or multivariate analyses. A preference for butter over oil or margarine is positively associated with PP in both types of analysis.

Other diseases: Hypertension is positively and significantly associated with PP in univariate analysis, but is of borderline significance in multivariate analysis $(\mathrm{N}=72)$. Peptic ulcer disease $(N=27)$ has a borderline significance in multivariate analysis with a negative association, but no relationship was found by univariate analysis.

\section{Agricultural Chemicals}

16 to $30 \%$ of the detectors picked up pesticides (carbamates and organic phosphorus compounds) in the air, between the houses in the residential area of the kibbutzim, at least 500 metres away from the site where pesticides were sprayed by airplanes. Herbicides (paraquat and diquat) as well as pesticides (mancozeb, organic phosphorus compounds) were detected in the soil of the fields, around the kibbutzim and in the soil of the residential area of the kibbutzim, unrelated to the time of the aerial spread.

\section{Discussion}

In the present study we attempted to identify some of the epidemiological factors which contribute to the high rate of Parkinson's disease and extrapyramidal signs which we previously described in adjacent kibbutzim ("cluster" kibbutzim) located in the Northwestern part of the Negev. The founder generation of the kibbutz (persons over the age of 50) consists mostly of unrelated people born in different countries. A great proportion of them, accumulated a considerable number of years in agricultural occupations. This population is less mobile than its urban counterpart and except for military service and perhaps some brief missions outside the kibbutz, they have spent most of their adult life in the kibbutz. The members of the kibbutzim eat all their meals in a common dining room. Until the early 1960s the "cluster" kibbutzim got their drinking water from wells drawing on the same aquifer, and thereafter from the north of the country via the National Water Carrier. The fields and the orchards are located at the near periphery of the residential areas of the kibbutzim and the latter contain large areas of grass and trees. A high level of agricultural productivity is maintained through extensive use of pesticides and herbicides and irrigation with recycled sewage water from the most heavily industrialized areas of the country.

The present study reconfirmed the high prevalence of extrapyramidal signs (preparkinsonism) in asymptomatic subjects, over the age of 40 , in five kibbutzim, and especially in the "cluster" kibbutzim, two of which were previously studied. ${ }^{19-21}$ These signs, like the incidence of Parkinson's disease elsewhere, are increasing in frequency and severity with the age of the subjects. We found a strong correlation between the frequency and severity of these signs and the variable of field crop work. A 
Table 2: Logistic regression analyses, case-referent set, $\mathrm{N}=190$ (95 pairs) for epidemiology of pre-parkinsonism (PP).

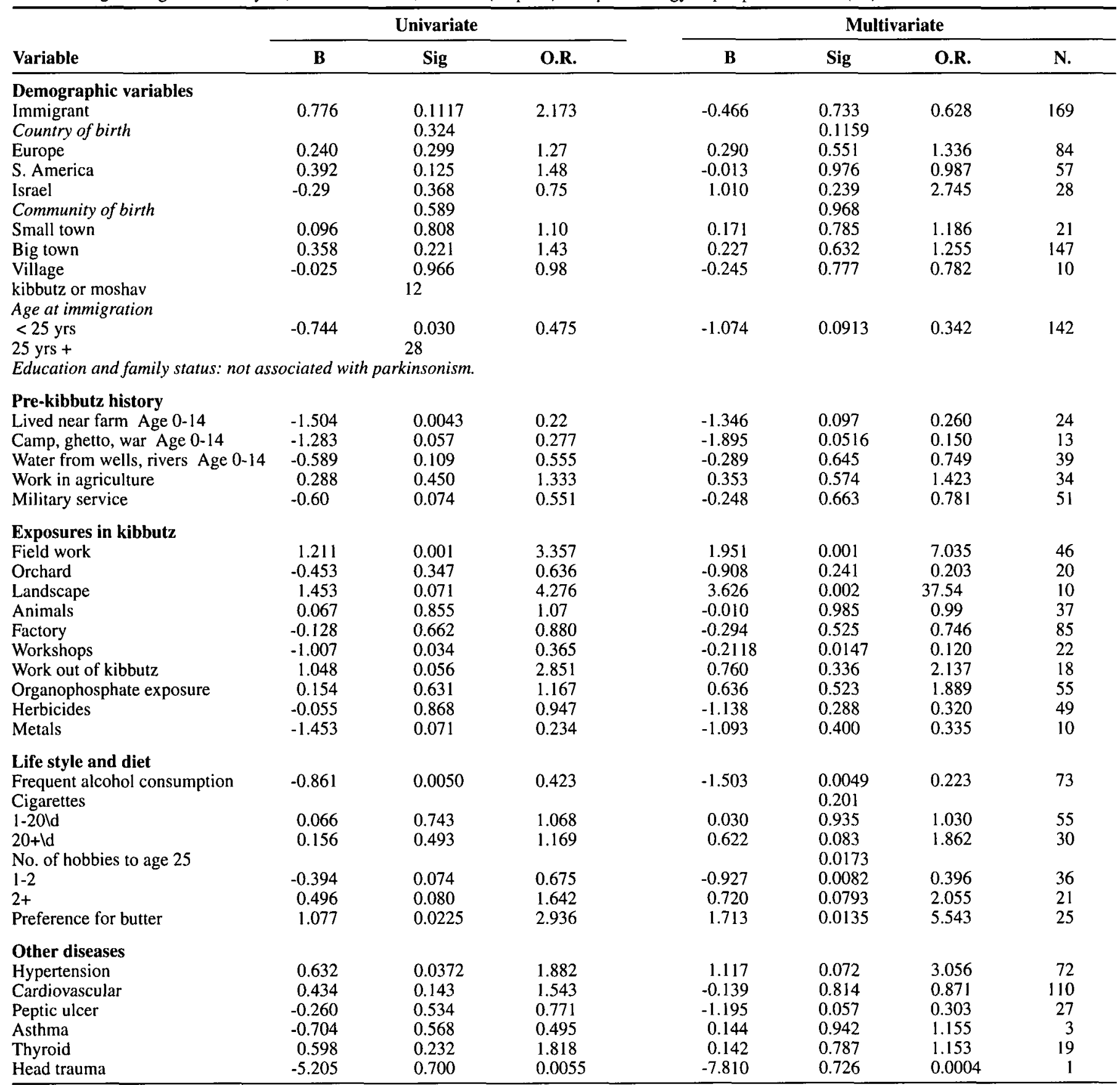

high Webster score, unilateral signs and bilateral extrapyramidal signs including rigidity and cogwheeling and resting tremor is considered as preparkinsonism. Early presence of motor signs and symptoms of Parkinson's disease, as well as non-motor signs (depression, constipation, seborrhea, impairment of olfactory perception, etc.) are sometimes revealed by retrospective analysis of patients' histories. Other isolated motor signs are sometimes considered as a manifestation of aging and not as early signs of Parkinson's disease. Duncan and Wilson ${ }^{24}$ examined a group of healthy elderly urban patients and found extrapyramidal signs, such as reduced arm swing (37\%), unspecified tremor $(11 \%)$ and increased tone $(2 \%)$. Another study, ${ }^{25}$ found tremor in 155 out of 356 subjects 65 or older. On follow-up (14 months), some subjects satisfied criteria for the diagnosis of Parkinson's disease. Another recent population study ${ }^{26}$ performed in two villages in Southern Germany found 45 out of 982 inhabitants older than 65 years to have signs of basal ganglia disorders. Seven of them, presenting two of the PD cardinal signs, were diagnosed as suffering from Parkinson's disease. Their signs were mild or moderate, on a scale of 1 to 3 . Bennett et al. ${ }^{22}$ in a study done on a random sample of 467 residents of East Boston, 65 years or older, found 159 persons to have parkinsonism. Twelve parkinsonian signs were sorted into four categories: bradykinesia, gait disturbances, rigidity and tremor and parkinsonism was defined as the presence of two or more parkinsonian sign categories. The preva- 
Table 3: Preparkinsonism (PP) by type of field crop (case-referent study).

\begin{tabular}{lcccc}
\hline Crop & & $\begin{array}{c}\text { Number of persons } \\
\text { without PP }\end{array}$ & $\begin{array}{c}\text { Number of persons } \\
\text { with PP }\end{array}$ & Sign \\
\hline Cotton & No & 94 & 1 & .0007 \\
& Yes & 80 & 15 & .02 \\
Potato No & 93 & 2 & \\
& Yes & 84 & 11 & .085 \\
Wheat No & 93 & 2 & \\
& Yes & 88 & 7 & .06 \\
Other & No & 89 & 6 & \\
& Yes & 80 & 15 & \\
\hline
\end{tabular}

lence of parkinsonism in this population increased with age and was $14.9 \%$ in people 65 to 74 years of age, $29.5 \%$ in those 75 to 84 years and reached $52.4 \%$ in people older than 85 years. Waite et al. ${ }^{27}$ have studied a random sample of 647 community dwelling subjects older than 75 years (average age 81 years) in Australia. They found gait slowing (diminished arm swing, postural flexion and bradykinesia) in $21 \%$ of the subjects, and parkinsonism, diagnosed as a combination of bradykinesia and abnormalities of tone, in $5.1 \%$. Although, there are different methodological approaches, different populations and the description of the extrapyramidal signs and their quantification are not the same as in the present study, all these studies found a relatively high frequency of extrapyramidal signs in general population and the question arises as to whether these signs represent clinical signs of presymptomatic Parkinson's disease.

Case-control studies conducted elsewhere, reported an increased prevalence of Parkinson's disease among residents of rural communities which is possibly linked to well water use. ${ }^{28,29}$ Wong et al. ${ }^{13}$ also found that living in a rural environment and drinking well water are risk factors for Parkinson's disease and that the number of years living in such an environment was significantly greater than in the control subjects. A case-control study from Taiwan ${ }^{30}$ suggested a significant association between Parkinson's disease and rural environment, farming (rice growing) and herbicide and pesticide use (particularly paraquat). Farming was also reported to have been a more frequent occupation among parkinsonian patients than in controls. ${ }^{31}$ Koller et al. ${ }^{11}$ reported a statistically significant elevation in the number of years that Parkinson's disease patients had spent living in a rural environment as compared with controls. However, these authors did not find a difference between the patients and controls regarding farming as an occupation.

A case-control study done in Hong-Kong ${ }^{10}$ found that long duration of residence in rural areas, long term farming, the use of herbicides and pesticides and the consumption of raw vegetables were all interrelated and increased the risk for Parkinson's disease. A recent study from Spain, ${ }^{15}$ reconfirmed that rural living, well-water drinking and a positive family history of Parkinson's disease and postural tremor were associated with an increased risk for Parkinson's disease. Brains from asymptomatic rural people were shown to contain a lower count of dopaminergic neurons in the substantia nigra than those from asymptomatic towndwellers. ${ }^{32}$

In the present study we found a highly significant correlation between work on field crop and development of preparkinsonism, with the highest association being with work in cotton fields. The main difference between wheat and cotton is the extensive use of herbicides and pesticides in the latter crop, sug-

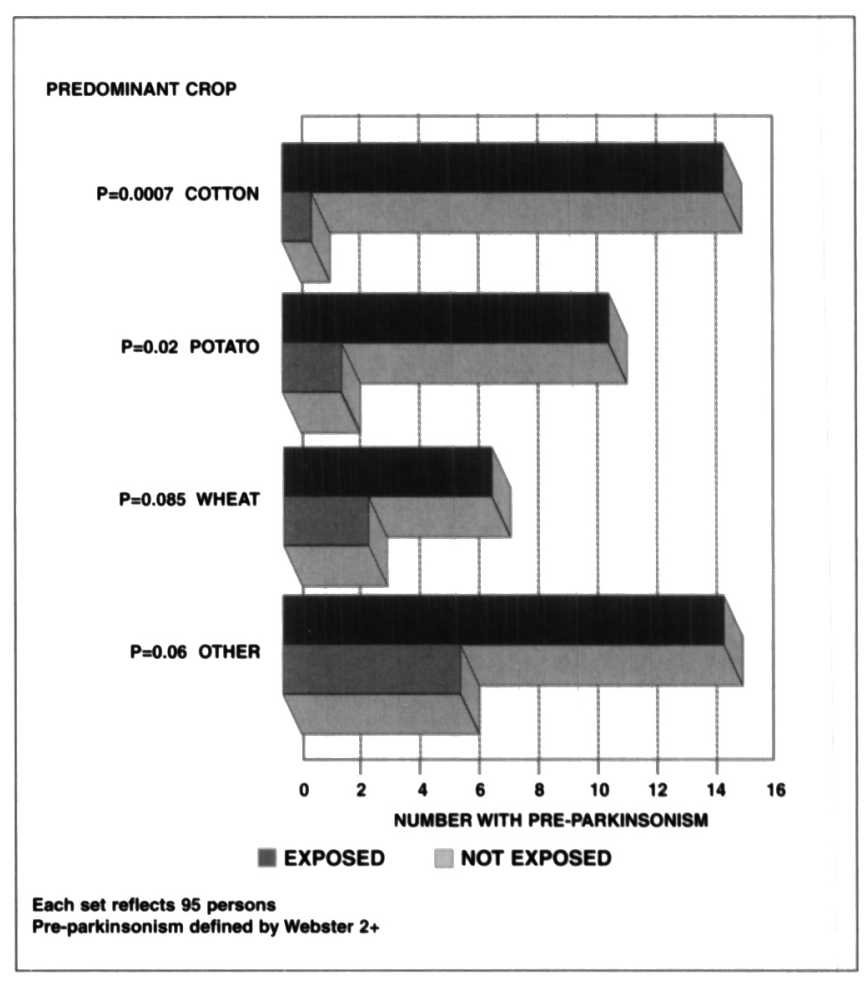

Figure: Pre-parkinsonism by field crop exposure: Case-referent study:

gesting that exposure to chemicals employed in agriculture may play a role in pathogenesis of preparkinsonism and possibly PD. As already stated, the fields in these kibbutzim are irrigated with recycled water brought from the most industrialized regions of Israel (e.g., Tel Aviv area) and a higher content of neurotoxins in this kind of water might be suspected. The preparkinsonian subjects reported higher exposure rates to organic phosphates than controls. We also found that beside occupational exposure, there has probably been a chronic repetitive passive exposure to pesticides and herbicides, as demonstrated by the detection of these chemicals in the air in the residential areas and by their presence in the soil between the houses.

As with the case of farming and rural background, there are still conflicting reports regarding the plausible connection between pesticide/herbicide exposure and the risk for Parkinson's disease. Barbeau and his colleagues ${ }^{9}$ found a very high correlation (0.967) between the incidence of the disease in the Province of Quebec and the level of pesticide use. Tanner et al..$^{33}$ in a study done in China reported a high exposure rate of Parkinson's disease patients to chemical, pharmaceutical, herbicide or pesticide industries before disease onset. Hubble et al., ${ }^{34}$ in a study done in Kansas, found that pesticide use, distinct from rural living, is the strongest predictor of Parkinson's disease. Semchuk et al. ${ }^{35-37}$ also found a threefold chance to develop this disease in association with herbicide use. They failed, however, to find any association between rural and farm living, well water drinking before age 45 and Parkinson's disease. Butterfield et al. ${ }^{6}$ found that Parkinson's disease was positively associated with insecticide exposure with past residence in a fumigated house and with herbicide exposure. Recently Seidler et al. ${ }^{38}$ reported on a significant association of Parkinson's disease with pesticides, in particular organochlorines and alkylated phosphates. This study failed to find any association between Parkinson's disease and 
other rural factors. A weaker association of Parkinson's disease with pesticides use was reported in a study from Spain, ${ }^{15}$ and Bennett et al ${ }^{39}$ did not find a change in incidence of the disease corresponding to utilization of any of herbicides or pesticides. Koller et al. " also, failed to find a difference between the Parkinson's disease patients and controls, regarding exposure to pesticides or herbicides at some time in their life. Wechsler et al..$^{31}$ found no strong association with pesticide, herbicide or fungicide exposures. They did find, however, several home pesticides or herbicides, e.g., Kleenup grass and weed killer, ortho Triox and Pestkil, to be reported more frequently by cases than controls.

Our study found a significant positive correlation between saturated fats content of the meals and the presence of preparkinsonian signs. This finding supplements the report by Golbe et al., ${ }^{40}$ of a negative correlation between Parkinson's disease and three items in the diet containing a high vitamin $\mathrm{E}$ content and unsaturated fats, e.g., nuts, plums and salad oil or dressing.

This study, like that recently published on a small cohort of preparkinsonian subjects ${ }^{20}$ showed a slight but not significant impairment in the olfactory discrimination ability of the preparkinsonian patients in comparison with the controls. It is interesting, that a similar finding was reported in MPTP induced parkinsonism by Doty et al. ${ }^{41}$

In light of the results of the present study we have recommended to these communities a stricter control of pesticides use in the residential vicinity of these kibbutzim. We feel that additional studies designed to investigate the epidemiology of preparkinsonism are warranted, as they may ultimately shed light on the etiology of Parkinson's disease. We present some of our findings and hypotheses in diagrammatic form in reference 42 .

\section{APPENDIX 1}

\section{Webster Parkinson's Disease Rating Scale}

1. Bradykinesia of hands

0 - pronation/ supination rate $>30 / 15 \mathrm{sec}$

1- lowering of the rate $20-25 / 15 \mathrm{sec}$

2-rate $16-20 / 15 \mathrm{sec}$

3- rate less than $15 / 15 \mathrm{sec}$

2. Rigidity

0 - not detectable

1- detectable rigidity in neck and shoulders

2- moderate rigidity in neck and shoulders

3- severe rigidity in neck and limbs, cogwheeling

3. Posture

0 - Normal

1- Head slightly flexed forward

2- Beginning arm flexion

3- Onset of simian posture

4. Upper extremity swing

0 - Normal swing

I- One arm less

2- One arm fails to swing

3- Both arms fail to swing

5. Gait

0 - Large steps. Turns about effortlessly

I- Short steps. Turns with several steps

2- Short steps: $10-15 \mathrm{~cm}$

3- Shuffling gait. Occasional blocking gait.Turns around very slowly
6. Tremor

0 - none

1 - less than 1 inch of peak to peak tremor in limbs at rest or in hand while walking

2- Tremor severe but not constant

3- Tremor constant and severe

7. Facies

0 - normal

1- detectable immobility

2- moderate immobility

3- frozen facies

8. Seborrhea

0 - none

1 - increased perspiration, secretion remaining thin

2- obvious oilness present

3- marked seborrhea

\section{ACKNOWLEDGEMENT}

Supported by a research fund granted (Dr. Y. Herishanu) by The Committee for Research and Prevention in Occupational Safety and Health, Israeli Ministry of Labor and Social Affairs. Authors are indebted to Dr. I. Wirguin for his suggestions and editorial assistance.

\section{REFERENCES}

1. Mutch WJ, Dingwall-Fordyce I, Downie AW, Paterson JG, Roy SK. Parkinson's disease in a Scottish city. Br Med J (Clin Res) 1986; 292: 534-536.

2. Herishanu YO, Goldsmith JR, Abarbanel JM, Weinbaum Z. Clustering of Parkinson's Disease in Southern Israel. Can J Neurol Sci 1989; 16: 402-405.

3. Calne DB, Langston JW. Aetiology of Parkinson's disease. Lancet Il 1983; 1457-1459.

4. Rajput AH, Uitti RJ, Stern W, Laverty W. Early onset Parkinson's disease in Saskatchewan-environmental considerations for etiology. Can J Neurol Sci 1986; 13: 312-316.

5. Tanner CM. Influence of environmental factors on the onset of Parkinson's disease (PD) (abst). Neurology 1986; 36 (Suppl 1): 215.

6. Butterfield PG, Valanis BG, Spencer PS, Lindeman CA, Nutt JG. Environmental antecedents of young-onset Parkinson's disease. Neurology 1993; 43: 1150-1158.

7. Tanner CM, Grabler P, Goetz CG. Occupation and the risk of Parkinson's disease (abst). Neurology 1990; 40 (Suppl 1): 422.

8. Jimenez-Jimenez FJ, Mateo D, Gimenez-Roldan S. Premorbid smoking, alcohol drinking and coffee consumption in Parkinson's disease. A case-control study. Mov Disord 1992; 7: 339 344.

9. Barbeau A, Roy M, Cloutier T, Plasse T, Paris S. Environmental and genetic factors in the etiology of Parkinson's disease. In: Yahr MD, Bergmann KJ, eds. Parkinson's disease. Advances in Neurology. New York: Raven Press, 1986; 45: 299-306.

10. Ho SC, Woo J, Lee CM. Epidemiologic study of Parkinson's disease in Hong Kong. Neurology 1989; 39: 1314-1318.

11. Koller W, Vetere-Overfield B, Gray C, et al. Environmental risk factors in Parkinson's disease. Neurology 1990; 40: 1218-1221.

12. Davanipour Z, Will AD. Residential histories in Parkinson's disease patients. Arch Neurol 1990; 47: 280-295.

13. Wong GF, Gray CS, Hassanein RS, Koller WC. Environmental risk factors in siblings with Parkinson's Disease. Arch Neurol 1991; 48: $287-289$

14. Stern M, Dulaney E, Gruber SB, et al. The epidemiology of Parkinson's disease: a case-control study of young-onset patients. Arch Neurol 1991; 48; 903-907.

15. Morano A, Jimenez-Jimenez FJ, Molina JA, Antolin MA. Risk-factors for Parkinson's disease: case-control study in the province of Caceres, Spain. Acta Neurol Scand 1994; 89: 164-170. 
16. Campanella G, Filla A, De Michele, et al. Etiology of Parkinson's disease: results of two case-control studies. Mov Disord 1990; 5 (Suppl): 31.

17. Campanella G, De Michele G, De Marco V, et al. Environmental and genetic risk factors in Parkinson's disease. Mov Disord 1992; 7 (Suppl 1): 76.

18. Goldsmith JR, Herishanu Y, Abarbanel JM, Weinbaum Z. Clustering of Parkinson's disease point to environmental etiology. Arch Environm Health 1990; 45: 88-94.

19. Herishanu YO, Goldsmith JR. Clustering of Parkinson's disease in Southern Israel. An endemic Parkinsonism-impaired vibration sense syndrome. In: Nagatsu et al., eds. Basic, Clinical and Therapeutic Aspects of Alzheimer's and Parkinson's Diseases. Plenum Press, NY, 1990; 2: 267-270.

20. Herishanu YO, Frisher S. Early Parkinsonism in a rural population of Southern Israel (abst). Mov Disord 1991; 6: 270.

21. Herishanu YO, Podgaietski M, Granovski R. Olfactory function in a cohort of preparkinsonian subjects. In: Korczyn AD, Monduzzi, eds. Dementia in Parkinson's Disease, 1994: 85-89.

22. Bennett DA, Beckett LA, Murray AM, et al. Prevalence of parkinsonian signs and associated mortality in a community population of older people. N Engl J Med 1996; 334: 71-76.

23. Doty RL, Shaman P, Dann M. Development of the University of Pennsylvania Smell Identification Test: a standardized microencapsulated test of olfactory function. Physiol Behav 1984; 32 : 489-502.

24. Duncan G,Wilson JA. Extrapyramidal signs in dementia of Alzheimer type. Lancet 1989, 2: 1392.

25. Khatter AS, Kurth MC, Merroto MA, et al. Continuing follow-up of tremor and Parkinson's disease in a retirement community: phase II (abst). Neurology 1996; 46: 378.

26. Trenkwalder C, Schwarz J, Gebhard J, et al. Starnberg trial on epidemiology of Parkinsonism in the elderly. Arch Neurol 1995; 52: 1017-1022.

27. Waite LM, Broe GA, Creasey $H$, et al. Neurological signs, aging, and the neurodegenerative syndromes. Arch Neurol 1996; 53: 498-502.

28. Rajput AH, Uitti RJ, Stern W, D, et al. Geography, Drinking Water Chemistry, Pesticides and Herbicides and the Etiology of Parkinson's Disease. Can J Neurol Sci 1987; 14: 414-418.

29. Tanner CM, Chen B, Wang W, et al. Environmental Factors in the Etiology of Parkinson's Disease. Can J Neurol Sci 1987; 14: 419-423.
30. Liou HH, Jeng JS, Chang YC, Chen RC. Environmental risk factors and Parkinson's disease: a case-control study in Taiwan (abst). Neurology 1996; 46: A349.

31. Wechsler LS, Checkoway H, Franklin GM, Costa LG. A pilot study of occupational and environmental risk factors for Parkinson's disease. Neurotoxicology 1991; 12: 387-392.

32. Thiessen B, Munoz D, Rajput AH, Desai H. Substantia nigra neuronal counts in normal rural and urban population (abst). Neurology 1988; 38 (Suppl 1): 348.

33. Tanner CM, Chen B, Peng M, et al. Environmental factors and Parkinson's disease: a case-control study in China. Neurology 1989; 39: 660-664.

34. Hubble JP, Cao T, Hassanein RES, Neuberger JS, Koller WC. Risk factors for Parkinson's disease. Neurology 1993; 43: 1693-1697.

35. Semchuk KM, Love EJ, Lee RG. Parkinson's disease and exposure to rural environmental factors: a population based case-control study. Can J Neurol Sci 1991; 18: 279-286.

36. Semchuk KM, Love EJ, Lee RG. Parkinson's disease and exposure to agricultural work and pesticide chemicals. Neurology 1992; 42: 1328-1335.

37. Semchuk KM, Love EJ, Lee RG. Parkinson's disease: a test of the multifactorial etiologic hypothesis. Neurology 1993; 43: $1173-$ 1180.

38. Seidler A, Hellenbrand W, Robra BP, et al. Possible environmental, occupational, and other etiologic factors for Parkinson's disease: a case-control study in Germany. Neurology 1996; 46: 12751284.

39. Bennet V, Rajput AH, Uitti RJ. An epidemiological survey of agricultural chemicals and incidence of Parkinson's disease. Neurology 1988; 38 (Suppl 1): 349.

40. Golbe LI, Farrell TM, Davis PH. Case-control study of early life dietary factors in Parkinson's disease. Arch Neurol 1988: 45: 1350-1353.

41. Doty RL, Singh A, Tetrud J, Langston JW. Lack of major olfactory dysfunction in MPTP-induced Parkinsonism. Ann Neurol 1992; 32: $97-100$.

42. Goldsmith JR, Herishanu YO, Podgaietski M, Kordysh E. Dynamics of parkinsonism and Parkinson's disease in residents of adjacent kibbutzim in Israel's Negev. Environm Research 1997; 73: 156-161. 